\title{
Accountable Party Identifier
}

National Cancer Institute

\section{Source}

National Cancer Institute. Accountable Party Identifier. NCI Thesaurus. Code 6117054.

A sequence of characters used to identify, name, or characterize the accountable party. 